\title{
Prevalence of delayed first permanent molar eruption among children 7 to 9 years old
}

\author{
Noor Hamiza Hani Hamsin*, Ratna Indriyanti*, Iwan Ahmad Musnamirwan* \\ *Departement Of Pedodontics, Faculty of Dentistry, Universitas Padjadjaran
}

\begin{abstract}
Introduction: Eruption is the moment of tooth emergence into the oral cavity. The emergence of the first permanent molar was followed by shedding of the deciduous incisors and as for permanent incisors eruption; it was taken as a point where the transition from primary dentition to permanent dentition begins with. The aim of this research is to determine the prevalence of delayed first permanent molar tooth eruption that occur among the children from 7 to 9 years old in Sekolah Dasar Negeri (SDN) Cisitu 1, SDN Coblong 4 and SDN Sekeloa 1. Methods: The method of choosing sample was simple random sampling. Out of 547 children from three Sekolah Dasar Negeri (SDN), only 71 children were selected randomly according to their ages, 7 to 9 years old. The method of this research was descriptive with surveying method. A clinical examination was done to determine the tooth eruption and data information was taken. Results: Out of 547 children from SDN Sekeloa 1, SDN Cisitu 1 and SDN Coblong 4 only 71 children were selected to take part in this research. They were randomly selected according to their age from 7 to 9 years old from each school Conclusion: This research shows that the delayed first permanent molar eruption among children in these samples of population were rarely happen.
\end{abstract}

Keywords: Eruption, First Permanent Molar Tooth, Children

\section{INTRODUCTION}

According to Suri (2004), eruption is used to indicate the moment of emergence of the tooth into the oral cavity. Racial, ethnic, sexual, and individual factors can influence eruption and are usually considered in determining the standards of normal eruption. Hence, there are many factors that influence the moment of emergence of the tooth into oral cavity.

As we know, during lifetime, human have two sets of teeth which are primary and permanent dentition. About 14 weeks in utero, the primary set of teeth begins to form prenatally and end or completed during 3 years old. Thus, the emergence of the first permanent molars follows by shedding of the deciduous incisors and the emergence of permanent incisors are where the transition from the primary dentition to the permanent dentition begins with. ${ }^{2,3}$

So, the permanent teeth replace the exfoliated deciduous teeth according to the sequence of eruption that may vary from different person. According to Ash and Nelson (2003), human dentition was usually categorized as primary, mixed and permanent dentition. The 
transition from primary to permanent dentition is of particular interest because of changes that may herald the onset of malocclusion and provide for its interception and correction. ${ }^{2,3}$ In addition, the first indication of tooth formation occurs as early as sixth week of prenatal life when jaws assumed their initial shape. Usually during birth, no teeth are visible. However, infant may born with erupted mandibular incisors. Development primary and permanent dentition continues during this period. Jaw growth follows the need for additional space posteriorly for additional teeth.

The predominant sequence of eruption of permanent tooth in individual jaw is first molar, central incisor, lateral incisor, and first premolar, second premolar, canine, second molar and third molar. ${ }^{2,3}$ True and significant deviations from accepted norms of eruption time are often observed in clinical practice. Premature eruption has been noted, but delayed tooth eruption is the most commonly encountered deviation from normal eruption time. ${ }^{4}$

According to Ash and Nelson (2003), delayed eruption of primary teeth may arise from either systemic or local factors. ${ }^{2,3}$ If in the absence of congenital disorders, dental disease, or trauma, the first teeth in permanent dentition begin to appear in oral cavity at mean age of 6 . The last emerge of this primary dentition at a mean age of 28 months. So due to association with prematurity or low birth weight, delayed eruption in children could happen. Early loss of primary tooth may also cause delayed eruption for children.

Delayed eruption of both dentitions may occur in associate with Down syndrome, Turner's syndrome, nutritional abnormalities, endocrine disorders, or cleidocranial dysplasia. Permanent tooth eruption often delayed or failed in eruption because of supernumerary teeth. ${ }^{5}$ This may happen because of primary teeth failed to resorb. Hereditary gingival fibromatosis may associated with delayed eruption because of local effect whereby teeth unable to penetrate the enlarged and thickened gingiva.

Moreover, truly localized cause of delayed eruption includes ectopic crypt position. This situation often affects maxillary and mandibular permanent canines or may present with impaction of maxillary first permanent molars against distal aspect of adjacent primary second molar. ${ }^{5}$ More generalized failure of eruption according to Holt (2000) in a journal is rare but may associated with a variety of systemic cause such as impacted teeth, iatrogenic causes, Down syndrome and many others. The objective of this research being proposed is to assess the prevalence of delayed of permanent first molar tooth eruption that occur among children from 7 to 9 years old in SDN Cisitu 1, SDN Coblong 4 and SDN Sekeloa 1.

\section{METHODS}

The type of research conducted is descriptive with surveying method. This research was done descriptively with surveying method in children from 7 to 9 years old at SDN Cisitu 1, SDN Coblong 4 and SDN Sekeloa 1 to count the prevalence for delayed permanent first molar tooth eruption in this population. The method of choosing sample is simple random sampling because this research only involves three schools which are a small population of sample. The samples being choose by using Yamen's formula.

Certain considerations included in this research are boy and girl students from SDN Cisitu 1, SDN Coblong 4 and SDN Sekeloa 1 from 7 to 9 years old, ready to be observed and cooperative, ready to give informed consent.

The equipments used during this research were basic dental instruments such as explorer, mouth mirror, tweezers and tray; masks, gloves, torchlight, table on development of tooth, form of data for their parents, and informed consent form. Materials used were cotton palate and alcohol $70 \%$.

\section{RESULTS}

Out of 547 children from SDN Sekeloa 1, SDN Cisitu 1 and SDN Coblong 4 only 71 children were selected to take part in this research. They were randomly selected according to their age from 7 to 9 years old from each school. Moreover, clinical examination should be done methodically and must begin with the overall physical evaluation of the patient. ${ }^{4}$ Total numbers of children in those three schools and the results of delayed first permanent molar tooth eruption throughout the period of research were shown in Table 1. and Table 2. The amount of children that came 
Table 1. Total Numbers of Children from Three SDN

\begin{tabular}{cccc}
\hline School/Age (years) & $\mathbf{7}$ & $\mathbf{8}$ & $\mathbf{9}$ \\
\hline SD Sekeloa 1 & 8 & 3 & 2 \\
SD Cisitu 1 & 20 & 6 & 3 \\
SD Coblong 4 & 14 & 10 & 5 \\
\hline
\end{tabular}

Table 2. Number of Delayed First Permanent Molar Eruption

\begin{tabular}{clll}
\hline School/Age (years) & $\mathbf{7}$ & $\mathbf{8}$ & $\mathbf{9}$ \\
\hline SD Sekeloa 1 & 1 & 0 & 0 \\
SD Cisitu 1 & 1 & 2 & 0 \\
SD Coblong 4 & 0 & 0 & 0
\end{tabular}

for being assessed is listed entirely in Graphic 1. And Graphic 2. shows the number of normal and delayed eruption of first permanent molar tooth eruption according to each school.

The Graphic 3. shows the percentage of delayed first permanent molar eruption happen in between children 7 to 9 years old in SDN Sekeloa 1, SDN Cisitu 1 and SDN Coblong 4. The results shows that
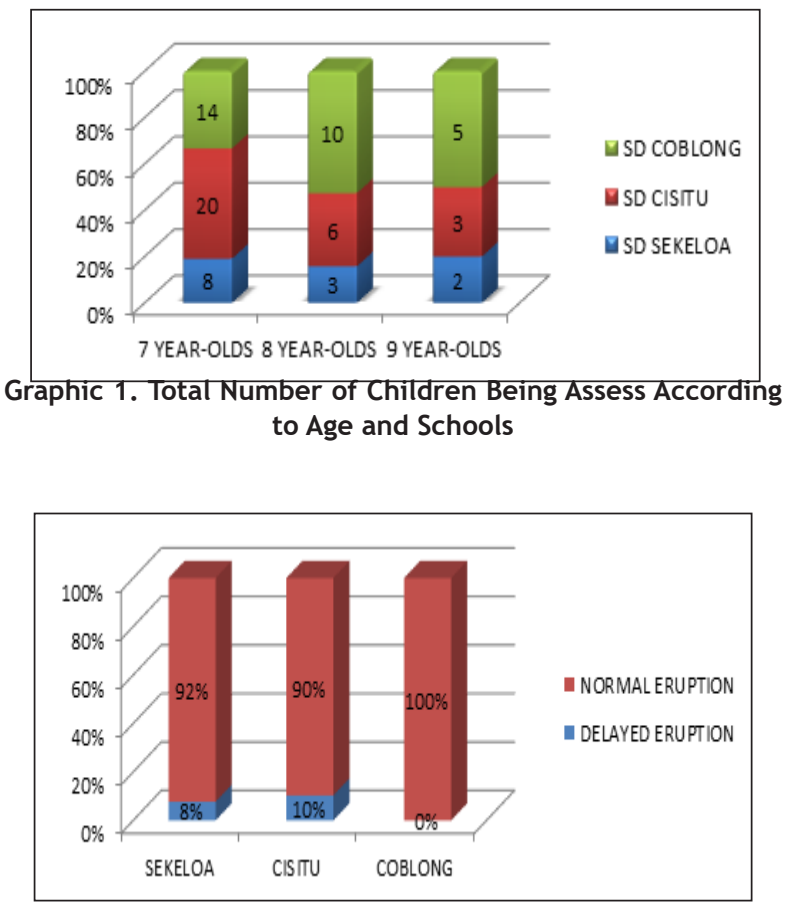

Graphic 2. Fraction of Delayed and Normal Tooth Eruption of First Permanent Molar Tooth in Children from Three Schools

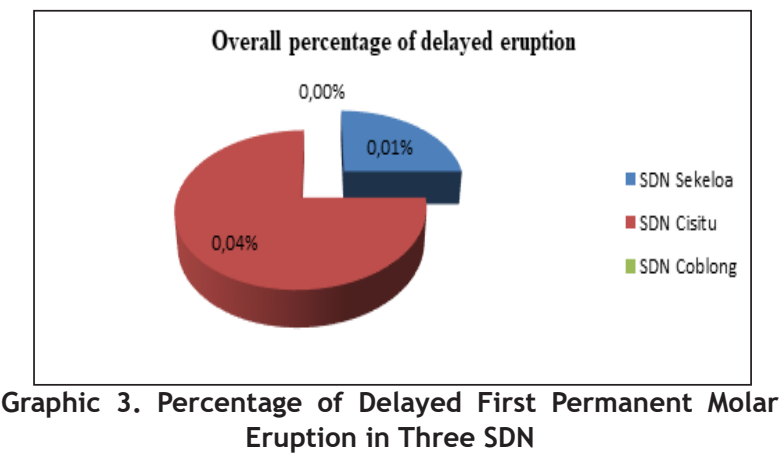

SDN Cisitu 1 has a greater number of children with delayed first permanent molar eruption than SDN Sekeloa 1, meanwhile SDN Coblong 4 happen to be nobody having this disorder. More than 50 percent from the total numbers of delayed eruption derived from SDN Cisitu 1.

Besides that, only $1.41 \%$ of delayed first permanent molar eruption happens in SDN Sekeloa 1 and $4.23 \%$ from SDN Cisitu 1, meanwhile the rest of the sample are going through a normal eruption time of teeth. The Graphic 4. and 5. show the percentage of delayed and normal of first permanent molar tooth eruption in SDN Sekeloa 1 and SDN Cisitu 1.

As we know, there is no delayed first permanent molar eruption happen in SDN Coblong 4 and this explains why the researcher did not include the bar chart for this school. The Graphic 6. shows the overall percentage of delayed and normal first permanent molar eruption from those three SDN being observed.

This research was done at three Sekolah Dasar Negeri (SDN) in Kecamatan Coblong which were SDN Sekeloa 1, SDN Cisitu 1 and SDN Coblong 4 at north of Bandung, West Java, Indonesia. It was

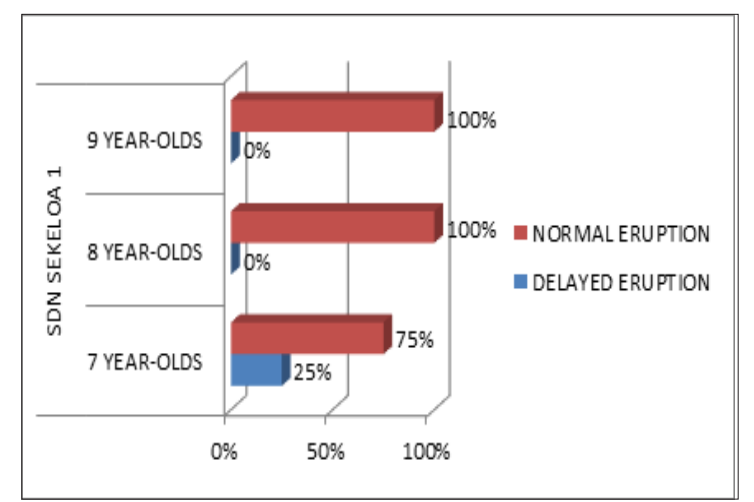

Graphic 4. Percentage of Delayed and Normal Tooth Eruption in SDN Sekeloa1 According to Children Ages

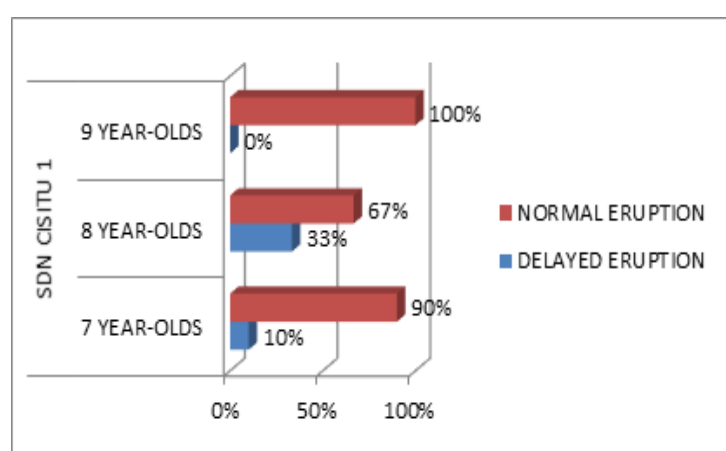

Graphic 5. Percentage of Delayed and Normal Tooth Eruption in SDN Cisitu 1 According to Ages 


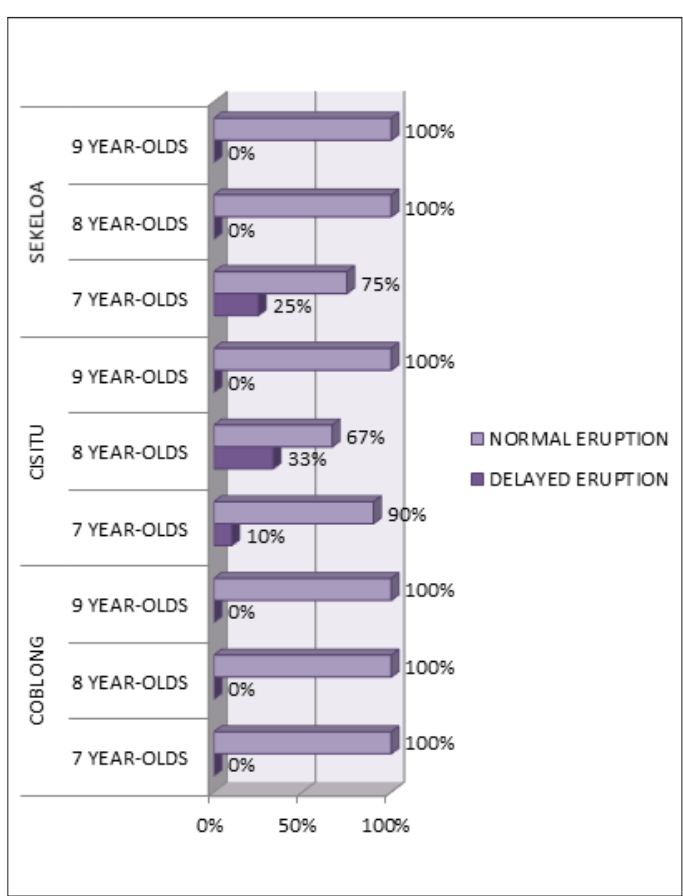

Graphic 6. Overall Percentage of Delayed and Normal Tooth Eruption for Three SDN

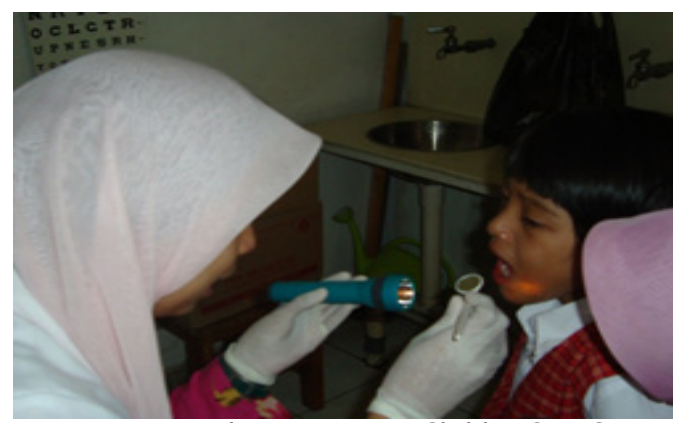

Figure 1. Researcher Examine a Child in SDN Cisitu 1

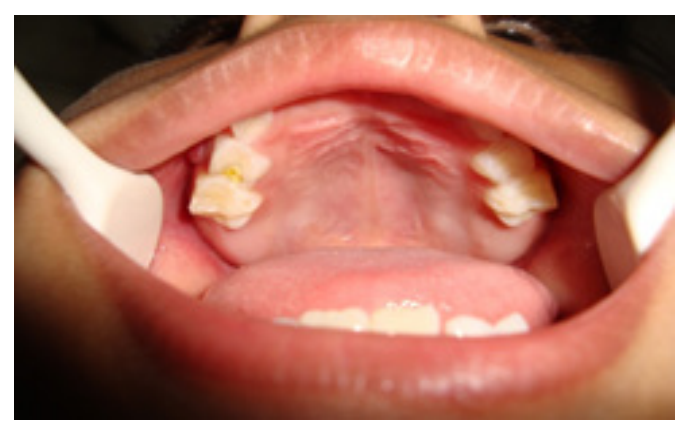

Figure 2. A Subject from SDN Cisitu 1 with Delayed Eruption

carried out by using two methods which were data information form and also clinical examination to 71 children from those three schools. The children from 7 to 9 years old in those three schools were chosen randomly by researcher. During the first day, researcher went to each school to give out the data form as well as informed consent to those parents whom their child suite the inclusion criteria for this research. Instruction also given to them on getting their parents' agreement before the clinical examination had been done.

On the other day, the data forms were collected and the clinical examination was done to all the children. The eruption of first permanent molar tooth on each region for each child was being observed. Delayed first permanent molar tooth eruption was measured according to either the first permanent molar tooth has erupted or has not erupted yet during the day that the clinical examination was held at each school.

The terms delayed tooth eruption is used after calculating the age of children and \pm 2 Standard Deviation (SD) according to the suitable age of eruption for each tooth. For this research, data were collected for the first permanent molar tooth eruption which normally was in children of 6 to 7 years old. Thus, after the children's age was 7 years and 5 months, they were considered as delayed eruption of first permanent molar tooth. ${ }^{2,3}$

As we know, the purpose of this research was to determine the prevalence of delayed first permanent molar eruption that occurs among children from 7 to 9 years old in three SDN as shown in Figure 4.1. The fact state that the normal eruption for first permanent molar tooth in children is between 6 to 7 years old (Ash and Nelson, 2003)..$^{2,3}$

There were many obstacles encountered during this research and the most important part was that we needed parents to come along with their children, but only a few came. As the first permanent molar erupt, the mandible incisors also go through the same process.

The picture in Figure 4.2 shows an example of a child aged 7years 5 months 16 days who had delayed eruption of first permanent molar. This delayed first permanent molar eruption phenomenon mostly happened in SDN Cisitu 1. From the survey on the map, SDN Cisitu 1 has the longest distance to a health centre rather than SDN Coblong 4 and SDN Sekeloa 1. Furthermore, SDN Cisitu 1 has the highest number of students there. This is different from SDN Sekeloa 1 and SDN Coblong 4. SDN Clsitu 1 surrounded by lesser number of schools around it, differs from SDN Sekeloa 1 and SDN Coblong 4 which have many other schools nearby. Even though the data on nutrition that influence on permanent tooth 
emergence are scarce, there are still evidences that chronic malnutrition extending beyond the early childhood is correlated with delayed teeth eruption. ${ }^{6}$ Moreover, delayed eruption was often reported in patients suffering from essential nutrient deficiency. ${ }^{4}$ Growing tissues that need high metabolic might be an influence for the eruptive process too. ${ }^{7}$ In addition, from an interview between researcher and the principle of each Sekolah Dasar Negeri (SDN), SDN Cisitu 1 was built in 1951.

Most of the parents at this area earned moderate to low income every month. Some of the children get their scholars from Yayasan Hari Mukti to pay for their living expenses because their parents cannot afford to give them pocket money. This showed that the socio-economic level in this area were moderate to low level of earning roughly.

Early tooth loss is usually caused by lack of vitamins, calciums and many other nutritions and the result from the observation explains why in this population, most of the children were prevented from having early tooth loss and also leads to rarely delayed tooth eruption. SDN Sekeloa 1 was located near to the Rumah Sakit Gigi dan Mulut which was about 500 metres while SDN Coblong 4 was located near to the Puskesmas Dago. At SDN Cisitu 1, there was a dental chair, but recently, they had stopped using it because of some economy problems.

They could not afford to pay the dentist to come and examine the children. The population in SDN Cisitu 1 can be concluded as poor because most of the parents could not well afford their children to go to school and for a treatment for their children.

As stated before, socioeconomic could be one of the factor of delayed tooth eruption and this situation explains why SDN Cisitu 1 has generated more children that having delayed first permanent tooth eruption than the others. Besides that, from the observations and data gathered, this population rarely had consultation and treatment with the dentist. Most of them rarely went to the dentist and some of them had never been to the dentist during their life time. This could lead them to have lack of oral health information. As for systemic disease, the children in this sample did not have any of serious systemic disease. The hormonal disorder also happens not to induce in this population. ${ }^{8}$ Moreover, variation in the normal eruption of teeth is a common finding, but significant deviations from established norms should alert the clinician to further investigate the patient's health and development. ${ }^{4}$

\section{CONCLUSION}

Prevalence of children having delayed first permanent molar eruption from this research rarely happen in the community.

\section{REFERENCES}

1. Suri L, Gagari E, Vastardis H. Delayed tooth eruption: pathogenesis, diagnosis, and treatment. A literature review. Am J Orthod Dentofacial Orthop. 2004 Oct;126(4):432-45. DOI: $10.1016 /$ j.ajodo.2003.10.031

2. Ash MM, Nelson SJ. Introduction to Dental Anatomy. Pp 1-2 in Dental Anatomy, Physiology and Occlusion. $9^{\text {th }}$ ed. SAUNDERS, St. Louis.

3. Ash, M. M; and S. J. Nelson. 2003. Development and Eruption of the Teeth. Pp 32-60 in Dental Anatomy, Physiology and Occlusion. SAUNDERS, St. Louis.

4. Suri L, Gagari E, Vastardis H. Delayed tooth eruption: Pathogenesis, diagnosis and treatment. A literature review. J. Orth Dent Ort. 2004;126(1):432-45.

5. Welbury R. Guggal RMS, Hosey MT. Pediatric Dentistry $3^{\text {rd }}$ ed. Oxford. University Press. 2005. 315-318. pp

6. Psoter W, Gebrian B, Prophete S, Katz R, Reid B. Effect of early childhood malnutrition on tooth eruption in Haitian adolescents. J. of Community Dent Oral Epidemilogy. 2008;36(1):179-89.

7. Moyers RE. Handbook of orthodontics $4^{\text {th }}$ ed. Chicago: Year Book Medical Publishers. 1988 173. pp

8. Almonaitiene RI. Balciuniene; and J. Tutkuviene. Factors influencing permanent teeth eruption. Part one-general factors. J Stomat, Baltic Dent Maxl. 2010;12(1):67-72. 